\title{
Budget analysis of FIFE 1987 Sonde Data
}

\author{
Alan K. Betts and J. H. Ball \\ Atmospheric Research, Pittsford, Vermont
}

\begin{abstract}
Mean thermodynamic profiles are presented for the daytime convective boundary layer evolution for three groups of sunny days in late June and early July, August, and October using data from the First International Satellite Land Surface Climatology Project (ISLSCP) Field Experiment (FIFE) 1987 Kansas experiment. Budget models for the mixed layer evolution and the boundary layer rise are used to estimate the boundary layer top entrainment parameter. A value of $A_{R}=0.44 \pm 0.21$ is found for the mean ratio of the inversion level virtual heat flux to the surface virtual heat flux.
\end{abstract}

\section{Introduction}

Over land in the daytime, the incoming solar radiation drives a strong diurnal cycle in the surface temperature and the surface fluxes of sensible and latent heat. A nearly well mixed boundary layer (BL) forms, which grows in depth with time, as it entrains or mixes in warmer, drier air from above. The balance between the surface fluxes and these entrainment fluxes determines the diurnal evolution of mixed layer properties, particularly potential temperature and mixing ratio. These thermodynamic parameters and the $B L$ depth in turn determine whether BL clouds form and whether these develop into deep convective clouds which precipitate, releasing latent heat to the atmosphere. This $\mathrm{BL}$ evolution is hard to simulate in global forecast and climate models, because the entrainment process must be parameterized, and we do not accurately know typical entrainment rates at BL top over land. The mixed layer model for BL growth was originally proposed by Ball [1960], and it was developed by Lilly [1968] for stratocumulus and by Betts [1973], Tennekes [1973], and Carson [1973] for dry convective BLs. This model, which has been widely used for nearly two decades, predicts BL growth by parameterizing the downward virtual flux of sensible heat at the BL-top inversion as a fraction $\left(A_{R}\right)$ of the surface virtual sensible heat flux (see (13) below). Stull [1976, 1988] reviews the estimates of $A_{R}$ from observational studies over the years and concludes $A_{R} \approx 0.2$ in unstable BLs, when the mechanical generation of turbulence is small. This value is supported by laboratory tank experiments and numerical BL simulations using large eddy models. Other papers [e.g. Zeman and Tennekes, 1977; Driedonks, 1982] have extended this model to include mixing by the shear stress, which increases $A_{R}$. Dubosclard [1980] estimated BL entrainment over corn fields in France over a range of stabilities and found distinctly larger values of entrainment than suggested by many models. Several recent papers have estimated BL entrainment rates. Betts et al. [1990,1992] using aircraft data from the First International Satellite Land Surface Climatology Project (ISLSCP) Field Experiment (FIFE)

\section{Copyright 1994 by the American Geophysical Union.}

Paper number 93JD02739.

0148-0227/94/93JD-02739\$5.00
[Sellers et al., 1988] found values of this entrainment parameter $A_{R} \approx 0.4$. Culf [1992] found similar high values from a study of BL growth over the Sahel.

BL-top entrainment is perhaps even more important in the moisture budget of the BL over land than in the thermal budget. Over grassland hills, as in FIFE, the surface latent heat flux peaks around $400 \mathrm{~W} \mathrm{~m}^{-2}$ at midday in spring and early summer, before the vegetation experiences moisture stress Kim and Verma, 1990]. In a 4-hour period centered on local noon, this evaporation would be sufficient to moisten a 100 -mbar-deep BL by $2 \mathrm{~g} \mathrm{~kg}^{-1}$. However, typically the mean mixing ratio in the BL stays nearly constant during the daytime, because of the large entrainment of dry air at BL top [Betts et al., 1992; Betts, 1992]. In this paper we shall use sonde data to make an independent estimate of BL growth and entrainment over the FIFE area. We again find a relatively large value for $A_{R} \approx 0.4$.

\section{Data Used}

\subsection{Sonde Data}

The sonde data were from radiosondes, which measured ternperature, wet bulb temperature and pressure. From these, potential temperature, $\theta$, and mixing ratio, $q$, were calculated. The sondes were tracked visually to $3000-4000$ m (in clear skies) by theodolite [see Sugita and Brutsaert, $1990 \mathrm{~A}, \mathrm{~B}$. The launch site was at $39^{\circ} 03^{\prime} 51^{\prime \prime} \mathrm{N}, 96^{\circ} 32^{\prime}-$ $30^{\prime \prime} \mathrm{W}$, in a valley near the north end of the FIFE site. Sondes were launched at roughly 90 -min intervals on almost all sunny days. The data are available from the FIFE Information System (FIS) as raw data, roughly every few millibar and also interpolated to 5-mbar standard levels. In this paper we used the 5-mbar data for IFC 2 and the slightly higher resolution raw data for IFC 3 and IFC 4 (because we had already processed it). For each sonde, we determined a BL depth from the top of the nearly well mixed layer, $p_{i}$ : this could be determined to typically \pm 5 $\mathrm{mb}$. We also estimated the top, $p_{t}$, of the inversion layer to a similar accuracy and noted $\theta_{t}$ and $q_{t}$ at this level. The individual BL profiles were then scaled in pressure using BL depth, by defining a scaled pressure

$$
\left.\hat{p}-\left(p_{s}-p\right) / p_{s}-p_{i}\right)
$$

where $p_{s}$ is the sonde surface pressure. All the $p$-level data were then interpolated to 0.05 intervals in $\hat{p}$. Sets of sondes 
for selected days could then be averaged, while preserving the vertical structure within the BL, following Betts [1976].

\subsection{Selection of Data}

Most sunny days had a series of sondes launched roughly every $90 \mathrm{~min}$. We selected all the days where the BL data appeared not to be contaminated significantly by precipitation for which sonde data were available. Table 1 shows the days selected for our analysis. There were seven in IFC 2, 13 in IFC 3 and six in IFC 4 (IFC denotes intensive field campaign: there were four in 1987). There were typically eight sondes each day. Very few sondes were missing because of balloon or instrument failure. The few gaps were filled by averaging adjacent sondes in time (in $p$ coordinates). Four sondes (in comparison with 51 launched) were interpolated in IFC 2; one in IFC 3 (compared with 104 launched) and two in IFC 4 (compared with 46 launched). At the end of a day the last sonde was missing occasionally (one sonde in IFC 2 and two in IFC 3), and for these the preceding sonde was replicated to give a homogeneous average time series, showing the end state near sunset. However, the last sonde average (near 2300 UT) will not be used in the budget analysis.

The surface flux data were taken from the fingl set processed by the FIFE Information System, in approximately January 1993. These data come from a variety of instruments and investigators (for details, see FIS archives). We selected 17 stations to generate a site mean average for the surface sensible and latent heat fluxes. The 17 stations selected were (old station numbers with new grid site values in parentheses) 2 (1916), 4 (2731), 8 (3129), 10 (3414), 12 (2915), 14 (2516), 16(4439), 18 (4439), 22 (4609), 24 (6912), 26 (8739), 28 (6943), 30 (4268), 36 (2655), 38 (1478), 40(1246), and 44 (2043). Stations 4, 16, 22, 26, 28 and 30 were eddy correlation sites; the remainder made their measurements by the Bowen ratio method.

\section{Diurnal Structure of the Boundary Layer (BL)}

We shall first show the time sequences of these averaged sonde profiles for the three IFCs.

\subsection{Averaged Sonde Profiles}

The time sequence of averaged profiles for the set of seven days in IFC 2 is shown in Figures 1 and 2 for $\theta$ and $q$ respectively. The sonde averages start soon after suarise at about 1200 UT (0700 CDT) and are roughly $90 \mathrm{~min}$ apart during the day: they are shown solid, dashed, and dotted in the time sequence shown in the legend. The averages were generated in scaled $\boldsymbol{p}$ coordinates and then converted back

Table 1. Analysis Days

\begin{tabular}{llc}
\hline IFC & \multicolumn{1}{c}{ Dates } & Total Days \\
\hline 2 & June 26,27; July $1,6,9-11$ & 7 \\
3 & August $6,7,9-11,14-21$ & 13 \\
4 & October 6-8, 11-13 & 6 \\
\hline
\end{tabular}

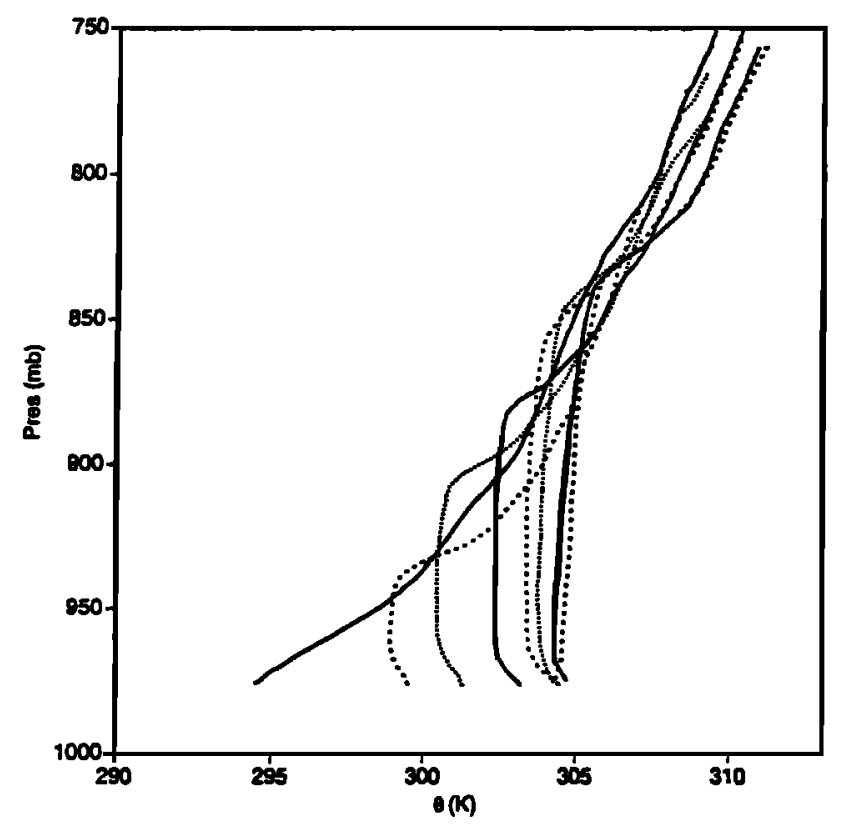

Figure 1. Potential temperature against pressure for time sequence of sondes (7-day mean) during Intensive Field Campaign 2 (IFC 2). (Mean sonde times are 1158, 1413, 1537, $1713,1843,2007,2143$, and 2248 UT.)

to pressure by multiplying by the average BL depth at each time. The surface sonde data should not be considered representative of the FIFE area. The characteristic warming and deepening of the daytime BL is visible in Figure 1. The cooling at BL top can also be seen as the mixed layer is pushed deeper by entrainment from overshooting thermals. Until local solar noon (at approximately 1820 UT), the lowest third of the BL is unstable in $\theta$ and virtual potential temperature, $\theta_{v}$, and stable above. There is a broad region of nearly constant $\theta_{v}$ between $0.2<\hat{p}<0.8$. The minimum in $\theta$ comes closer to the surface in $\not p$ in the afternoon soundings, as the surface superadiabatic layer weakens. In contrast, Figure 2 for mixing ratio, $q$, shows the BL deepening, but the BL mean value of $q$ changes by less than $1 \mathrm{~g} \mathrm{~kg}^{-1}$ during the day. The large evaporation at the surface is presumably nearly balanced by the downward mixing of dry air at BL top. As a result of this downward mixing of dry air, $q$ falls with height in the BL, as noted by earlier authors [e.g., Betts, 1976; Mahrt, 1976; Wyngaard and Brost, 1984].

Figures 3 and 4 show the $\theta$ and $q$ profiles for the 13-day average for IFC 3 in August. The BL warms a little more and grows a little deeper than in IFC 2 (June/July), since the surface sensible heat flux is higher in August, but the general pattern is rather similar to that seen in Figures 1 and 2. Once again, despite the large surface evaporation the mean BL mixing ratio changes rather little during the day as the BL deepens. The surface evaporation is a little smaller, the drop of mixing ratio at BL top is a little larger (than in IFC 2); and the equilibrium BL $q$ is a little lower.

Figures 5 and 6 show the $\theta$ and $q$ profiles for the 6-day average for IFC 4 in October. Conditions are much cooler and drier. The same pattern of BL warming and deepening is seen in Figure 5. Although it is fall and the days are 


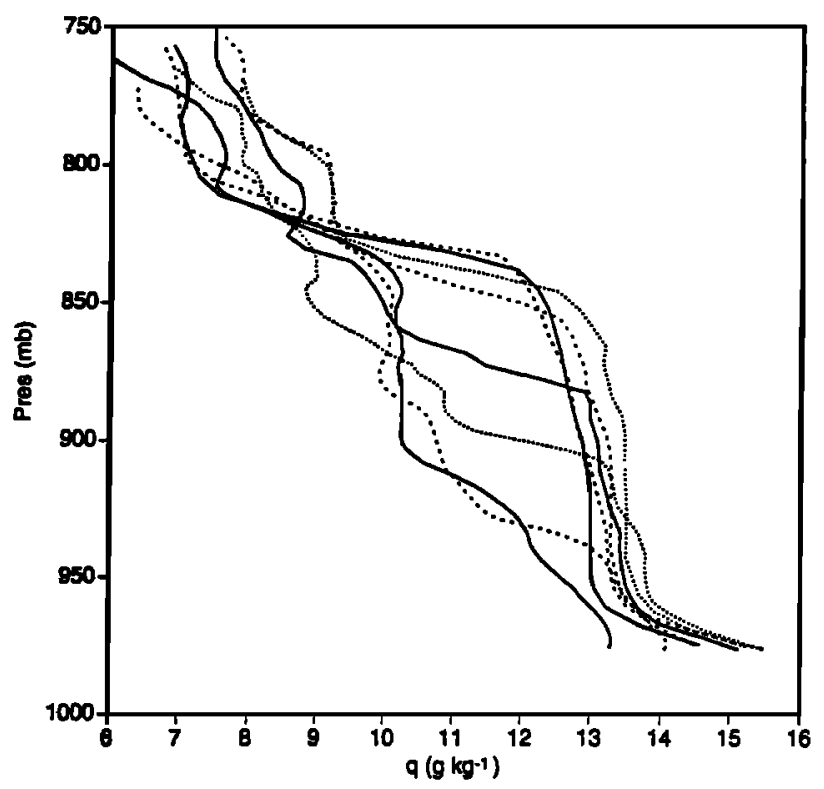

Figure 2. As Figure 1 for mixing ratio.

shorter, the BL warms and deepens faster, because the surface sensible heat (SH) flux is much larger (see Table 2 below). Figure 6 shows the very dry conditions in October, which are a sharp contrast to June/July and August. Both the surface evaporation and the entrainment of dry air are small, and once again mean $q$ barely changes during the day. The sonde humidity was measured by a wet-bulb thermistor, which freezes at lower elevations in October than in June/July and August. Consequently, some of the moisture profiles in Figure 6 only just reach BL top. We use these mean $\mathrm{BL}$ profiles here to estimate the entrainment rate needed in a mixed layer model to reproduce the observed BL growth and budget.

Figure 7 shows a further average of the eight BL profiles between 1400 to 1845 UT for the IFC 2 and IFC 3 averages. This averaging smooths the mean $\mathrm{BL}$ structure even further. For this average the convective velocity scale, defined as $w_{*}-\left(g h F_{s \alpha_{v}} / \bar{\rho} C_{p} \bar{\theta}_{\nu}\right)^{2 / s}$ is $1.38 \mathrm{~ms}^{-1}$, and the corresponding convective scale, $\theta_{v^{*}}$, defined from the surface virtual heat flux $F_{s Q_{v}}-\bar{\rho} c_{p} w_{*} \theta_{v *}$ is $0.085 \mathrm{~K}$.

One of the limitations of this composite thermodynamic analysis is that we average over other factors, such as wind shear, which may affect entrainment. Stull [1976B, 1988] has discussed the role of mechanical turbulence, generated by wind shears at the surface and across the inversion. The wind shears across the inversion are generally small in this data set $\left(\approx 2 \mathrm{~ms}^{-1}\right)$, but there is a very wide range of mean winds in the BL. In IFC 2, the mean BL wind is $8.8 \mathrm{~ms}^{-1}$ (with a range from 2 to $14 \mathrm{~ms}^{-1}$ ); in IFC 3, the mean is 8.0 $\mathrm{ms}^{-1}$ (range 3-16 $\mathrm{ms}^{-1}$ ); and in IFC 4 the mean is $7.3 \mathrm{~ms}^{-1}$ (range 3-12 $\mathrm{ms}^{-1}$ ). We do not have a sufficient number of days to stratify by wind speed in each IFC, so our composites for each IFC are purely thermodynamic ones, representative of a mean wind speed of about $8 \mathrm{~ms}^{-1}$. We will then, however, combine the IFC 2 and IFC 3 data and restratify them into two wind classes, to show the possible role of mechanically generated turbulence in driving entrainment.
The role of BL clouds in driving entrainment is also hard to quantify. We have an estimate of total cloud and high cloud from a whole sky camera. The difference, which includes BL clouds, is only one to two octas for the August and October averages, but peaks at four octas for the June/July average in mid-afternoon. The spread between lifting condensation level and BL-top, which is near zero in the June/July average, increases from June/July to October; suggesting also a decrease in cloudiness as the surface Bowen ratio increases.

\subsection{Comparison Between Surface and Mixed Layer}

Figures 1-6 show the BL profiles that are used for the budget calculations in the next sections. The budget model uses mixed layer averages, to calculate the time rate of change of the mixed layer (see equation (5) below). We now compare on a $(\theta, q)$ plot the time evolution of this mixed layer mean with the mean change near the surface as measured by an average of 10 surface portable automated meteorological (PAM) stations. Figure 8 shows the 7-day average for IFC 2. The left-hand set of points show the rise of $\theta$ and the small rise and fall of $q$ for the mixed layer (an average from $0.025<p<0.975$ ); the right-hand set are the 7 day average of the 10 PAM stations (at approximately $2 \mathrm{~m}$ ) interpolated to the same times. The UT times shown are the mean sonde times in the BL. The difference between the pairs of points at the same time, shown dashed, is closely the difference in $\theta$ and $q$ across the surface superadabatic layer. Correspondingly, the slope of the dashed line should be closely a measure of the surface Bowen ratio [Betts et al., 1990; Smith et al., 1991]. The difference in $q$ between surface and mixed layer appears to increase to about $2 \mathrm{~g} \mathrm{~kg}^{-1}$ during the day, so that $q$ at $2 \mathrm{~m}$ rises a little, while mixed layer $q$ generally falls. For the last pair of points at 2143

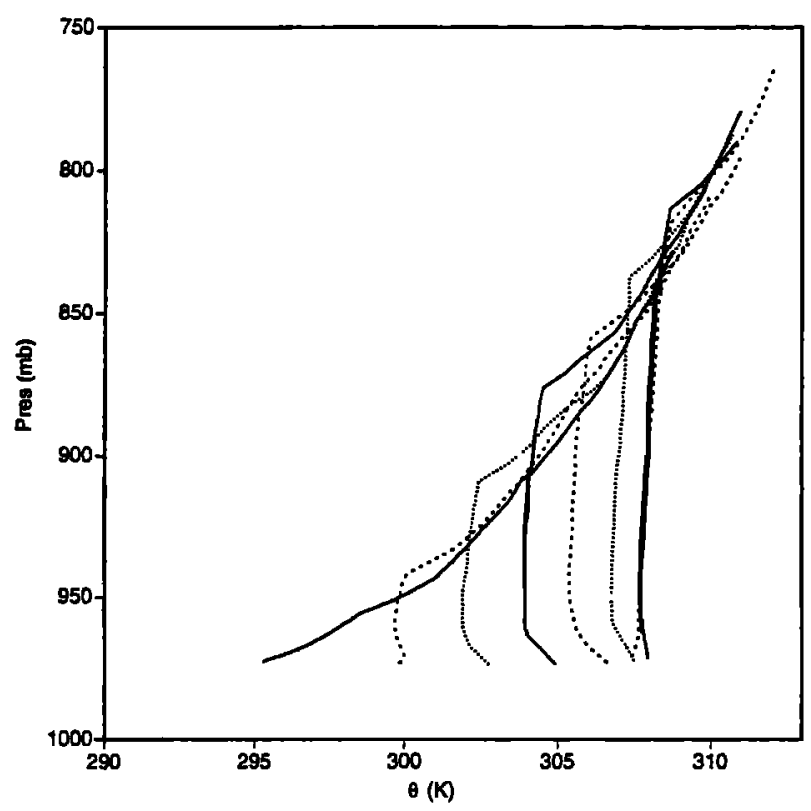

Figure 3. As Figure 1 for 13-day mean in IFC 3. (Mean sonde times are $1152,1411,1534,1713,1841,2010,2140$, and 2246 UT.) 


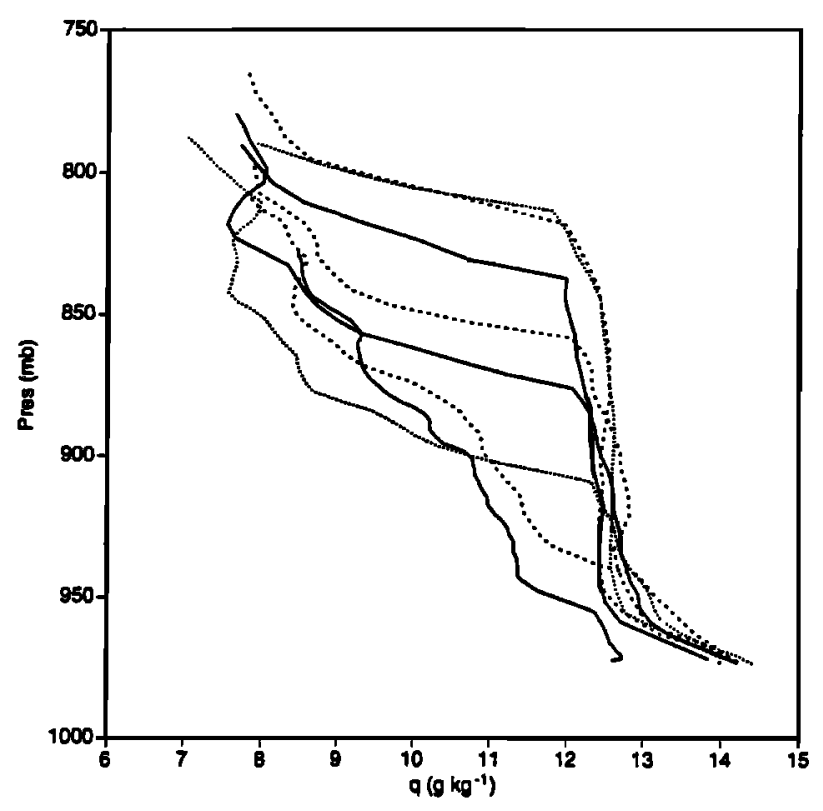

Figure 4. As Fig 3 for mixing ratio.

UT the surface has just started to cool from its maximum temperature. The PAM time series is a homogeneous one: an average of 10 sensors with continuous records in time, each averaged up to 30 mins. In contrast each sonde point comes from an average of seven measurements on different days, at similar times but each from different sondes. The sondes can both differ in their calibration, and any one can be unrepresentative in the sense that they are local 3-min averages as the sonde rises through a patch of $\mathrm{BL}$ air. If one sonde locally differs significantly from, say, an hourly or areal mean, then the corresponding average of the 7 days can be biased. As a result, inconsistencies between the curves for sonde and PAM data raise questions about the sonde average. For example, the sonde average at $1537 \mathrm{UT}$ seems relatively cool and moist compared to the general sequence. The dotted line, marked $\beta_{s}=0.35$, is the slope corresponding to the surface Bowen ratio [Betts, 1992] calculated from the measured surface fluxes from 1413 to $1713 \mathrm{UT}$. It confirms that the sonde average at $1537 \mathrm{UT}$ is probably too cool and moist: the dotted line $\beta_{s}-0.35$ corresponds to the dashed slopes at 1413 and 1713 UT much more closely than at 1537 UT. The budgets derived from the sondes for the time intervals 1413-1537 UT and 15371713 UT confirm this probable bias. However, rather than smooth the mixed layer time change, we shall integrate the budgets over the time period shown, which effectively smooths the fluctuations between sonde time steps, except at the endpoints. In fact the last sonde average at $2143 \mathrm{UT}$ is rather dry, and this appears to have impacted the average moisture budget for the day (see section 5.3). Whether any of the overall trend from 1413 to 2143 UT is related to horizontal advection, we cannot tell. We will assume in the mixed layer budget computation that after averaging over many days, the mean horizontal advection is small compared with the diurnal change, which is similar every day.

Figure 9 shows the comparison for the 13-day August average for IFC 3. The sonde averages and PAM averages appear to track well, if some qualitative allowance is made for the strengthening of the superadiabatic layer near local noon (1820 UT). The moisture fluctuation at 2010 UT does show up in the time step budgets but is smoothed in the average from 1411 to $2140 \mathrm{UT}$.

Figure 10 shows IFC 4 in October, where conditions are dry and the surface evaporation is small. The gradient of $q$ off the surface is very small, and the small differences in $q$ shown in Figure 10 should not be considered accurate, since the measurements are by different systems. The sonde and surface measurements agree on the general warming of the

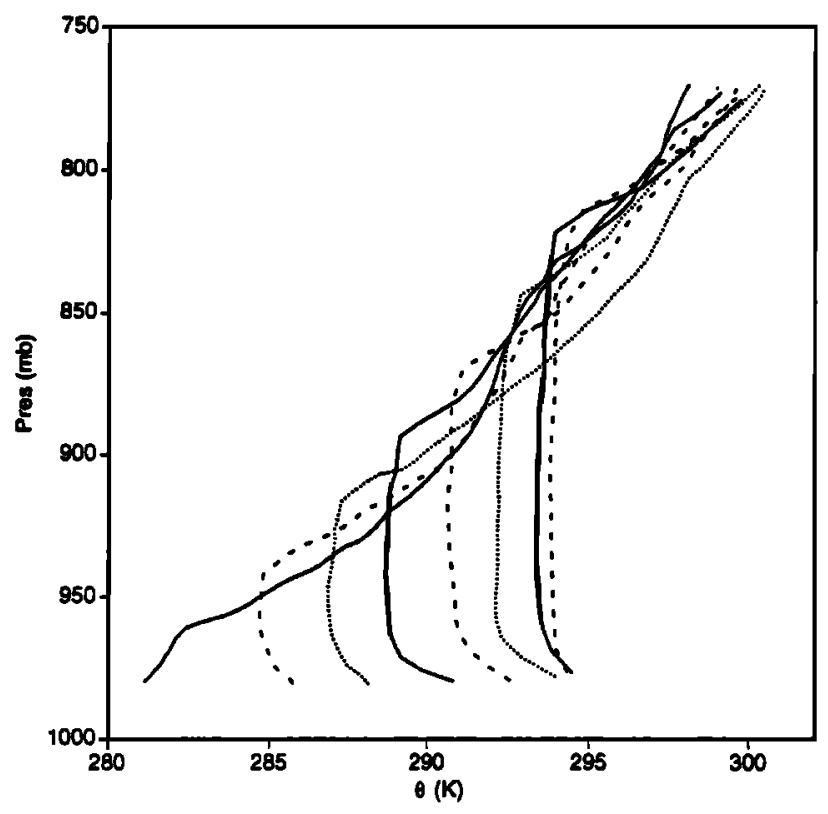

Figure 5. As Fig 1 for 6-day mean in IFC 4. (Mean sonde times are 1340,1457, 1602, 1653, 1810, 1934, 2053, and 2205 UT.)

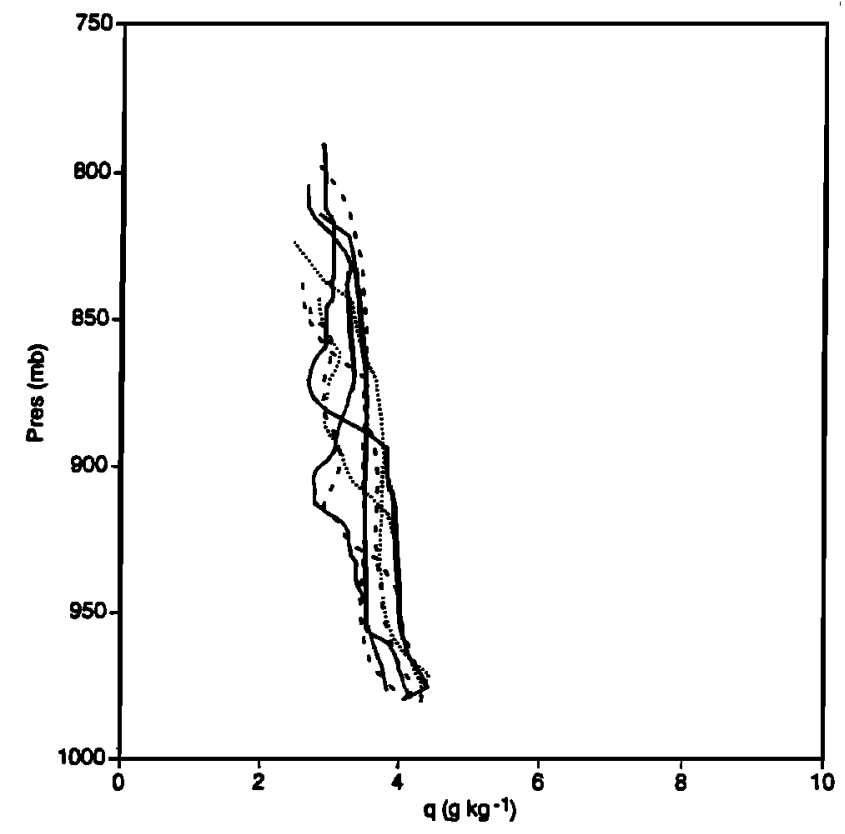

Figure 6. As Fig 5 for mixing ratio. 
Table 2. Estimation of $A_{R}$ from mixed layer budget.

\begin{tabular}{|c|c|c|c|c|c|c|c|c|c|}
\hline IFC & $\begin{array}{l}F_{\mathrm{st}} \\
\mathrm{W} \mathrm{m}^{-2}\end{array}$ & $\begin{array}{l}F_{s q} \\
\mathrm{~W} \mathrm{~m}^{-2}\end{array}$ & $\beta_{s}$ & $\begin{array}{l}F_{i \theta} \\
\mathrm{W} \mathrm{m}^{-2}\end{array}$ & $\begin{array}{l}F_{i q} \\
W \mathrm{~m}^{-2}\end{array}$ & $\beta_{t}$ & $\begin{array}{l}F_{\text {sev }} \\
\mathrm{W} \mathrm{m}^{-2}\end{array}$ & $\begin{array}{l}F_{\text {tav }} \\
\mathrm{W} \mathrm{m}^{-2}\end{array}$ & $A_{R}$ \\
\hline 2 & $\begin{array}{r}90 \\
\pm 9\end{array}$ & $\begin{array}{r}325 \\
+33\end{array}$ & $\begin{array}{r}0.28 \\
\pm 0.04\end{array}$ & $\begin{array}{c}-82 \\
\pm 22\end{array}$ & $\begin{array}{r}397 \\
\pm 55\end{array}$ & $\begin{array}{c}-0.21 \\
\pm 0.06\end{array}$ & $\begin{array}{r}113 \\
\pm 10\end{array}$ & $\begin{array}{c}-55 \\
\pm 22\end{array}$ & $\begin{array}{r}0.48 \\
\pm 0.20\end{array}$ \\
\hline 3 & $\begin{array}{r}119 \\
\pm 12\end{array}$ & $\begin{array}{r}285 \\
\pm 29\end{array}$ & $\begin{array}{r}0.42 \\
\pm 0.06\end{array}$ & $\begin{array}{r}-142 \\
\pm 25\end{array}$ & $\begin{array}{r}340 \\
\pm 53\end{array}$ & $\begin{array}{c}-0.42 \\
\pm 0.10\end{array}$ & $\begin{array}{r}138 \\
\pm 13\end{array}$ & $\begin{array}{l}-118 \\
\pm 26\end{array}$ & $\begin{array}{r}0.85 \\
\pm 0.20\end{array}$ \\
\hline 4 & $\begin{array}{r}233 \\
\pm 23\end{array}$ & $\begin{array}{r}52 \\
\pm 5\end{array}$ & $\begin{array}{r}4.46 \\
\pm .63\end{array}$ & $\begin{array}{c}-84 \\
\pm 32\end{array}$ & $\begin{array}{r}112 \\
\pm 39\end{array}$ & $\begin{array}{r}-0.75 \\
\pm .39\end{array}$ & $\begin{array}{r}237 \\
\pm 23\end{array}$ & $\begin{array}{r}-76 \\
\pm 32\end{array}$ & $\begin{array}{r}0.32 \\
\pm 0.14\end{array}$ \\
\hline Mean & & & & & & & & & 0.55 \\
\hline
\end{tabular}

BL during the day, although again we will assume that none is due to horizontal advection in our mixed layer budget analysis.

\section{Budget Analysis}

The mixed layer budget analysis used in this paper was outlined recently by Betts [1992], based on earlier papers. We shall extend it to estimate entrainment separately from the rise of BL top.

\subsection{Budget Equations}

Consider a scalar $\xi$ for which there are no sources and sinks in the boundary layer ( $\xi$ will stand for the two conserved variables $C_{p} \theta$ and $L q$ ). This satisfies the conservation equation

$$
D \xi \mid D t-\partial \xi / \partial t+\nu \cdot \nabla \xi-0
$$

This can be rewritten, using the continuity equation

$$
\nabla(\bar{\rho} v)-0
$$

where $\rho$ is mean air density, as

$$
\bar{\rho} \partial \xi / \partial t+\nabla(\bar{\rho} \nu \epsilon)=0
$$

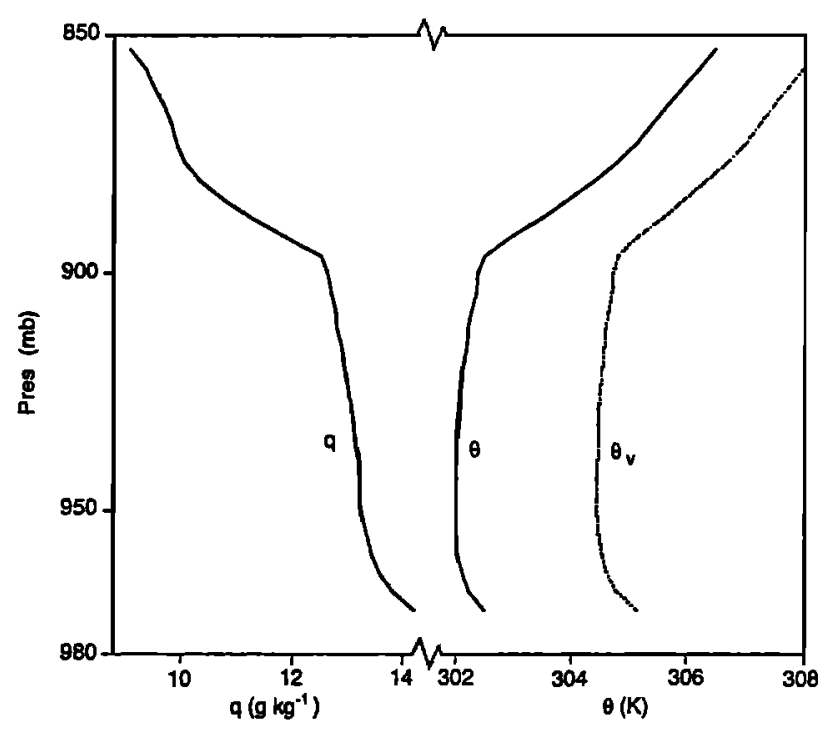

Figure 7. Average boundary layer sonde profile between 1400 and 1845 UT during IFC 2 and IFC 3 (summer).
Equation (1B) can be expanded in terms of horizontal averages and deviations to give, after rearrangement,

$$
\begin{aligned}
& \bar{\rho}[\partial \bar{\xi} / \partial t+\bar{u} \partial \bar{\xi} / \partial x+\bar{v} \partial \bar{\xi} / \partial y+\bar{w} \partial \bar{\xi} / \partial z] \\
& +\partial\left(\bar{u}^{\prime} \xi\right) / \partial x+\partial\left(\overline{v^{\prime} \xi}\right) / \partial y+\partial\left(\bar{\rho} \overline{w^{\prime} \xi}\right) / \partial z-0
\end{aligned}
$$

where $u, v$, and $w$ are the three wind components in the $x$, $y$, and $z$ directions, oriented in the conventional meteorological directions: to the east, north, and upward, respectively. Equation (2) has a time rate of change term, mean advection terms, and eddy transports by the boundary layer turbulence. Overbars denote horizontal averaging, and primes denote deviations from the horizontal average. The horizontal divergence of the horizontal eddy fluxes were found to be small on the basis of estimates made using aircraft data in FIFE, and they were therefore neglected.

The two mean horizontal advection terms are often not negligible on individual days in FIFE Betts et al., 1990, 1992]: they represent the change to the mean BL from warm (or cold), moist (or dry) advection into the FIFE area. However, because they do not always have the same sign, we assume here that averaged over a number of days, the average horizontal advection becomes small compared with the vertical eddy flux divergence which is similar on all days. We are forced to make this assumption because estimates of advection [e.g. Betts et al., 1992] are only available for a limited number of days and times when aircraft pattems were flown.

Estimates (using aircraft data from individual days) showed that the vertical advection $\bar{w} \partial \bar{\delta} / \partial z$ is an order of magnitude smaller than any other term: both because $\bar{w}$ (estimated from the horizontal divergence) is small, and because $\partial \bar{\xi} / \partial z$ is generally small within a nearly mixed BL. The vertical advection can be incorporated into the entrainment term at the top of the BL [Betts, 1992]. Our budget method of estimating entrainment (see 5.1) includes vertical advection, but our BL-growth method (see 5.2) neglects $\bar{w}$ in comparison with the daytime boundary layer growth rate. Equation (2) then reduces to (2')

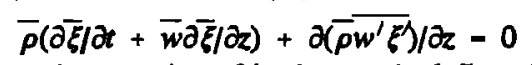

The last term in equation $\left(2^{\prime}\right)$ the vertical flux divergence, is a crucial one, since it is driving the time dependence of the atmospheric boundary layer (ABL). The mean surface fluxes over the FIFE area were found by averaging the 30 


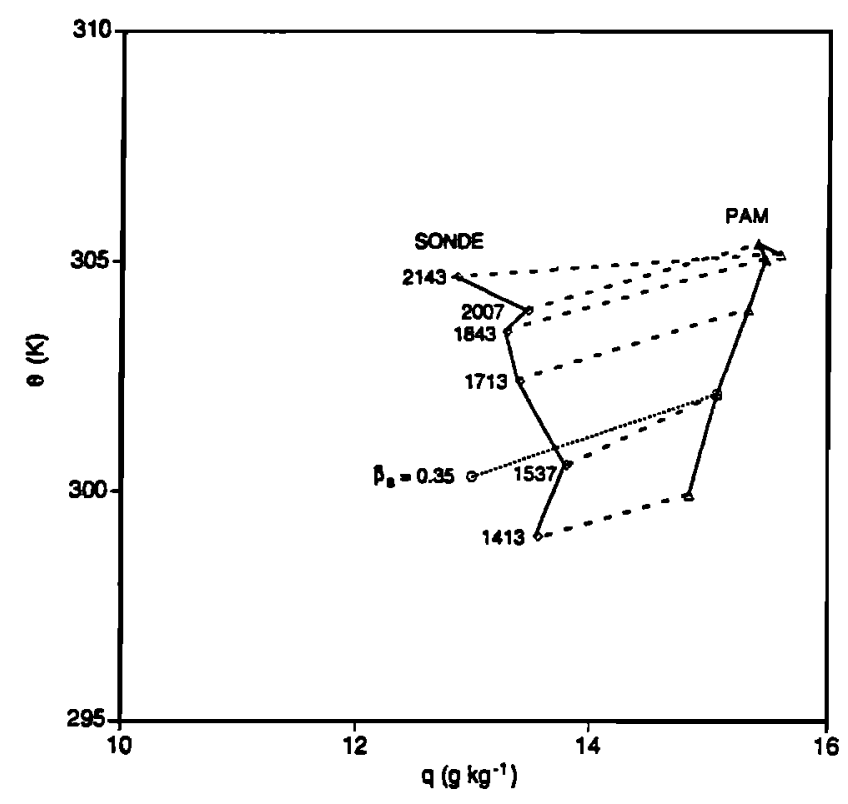

Figure 8. $(\theta, q)$ plot against time for 7-day mean in IFC 2 for mixed layer (sonde) and surface (PAM). Dotted line corresponds to surface flux Bowen ratio (see text).

min mean values from 17 selected surface flux sites, averaging over the days used for the sonde averages; and then interpolating and averaging these time-area means for the mean time periods between sondes. The turbulent mixing at the inversion is typically forcing the mixing or entrainment of warm dry air from above the capping inversion. This downward mixing of warm dry air means that the convective fluxes at the top of the mixed layer are typically a downward flux of $\theta$ and an upward flux of $q$. Since we know the time dependence of $\theta$ and $q$ from the sonde averages (Figures 8-10), we can integrate $\left(2^{\prime}\right)$ from surface to BL top to estimate these entrainment fluxes. This is the essence of our use of the mixed layer model.

\subsection{Mixed Layer Model}

Although there are weak gradients of $\theta$ and $q$ above the surface superadiabatic layer, the main characteristic of the dry ABL is that it is almost well mixed in $\theta$ and $q$, and the vertical profiles remain similar during the day (see Figures 1-6). Recognizing this, Betts [1973,1974], Tennekes [1973], Stull [1973], and Carson [1973] defined similar integral mixed layer model simplifications for the ABL by integrating $\left(2^{\prime}\right)$ from the surface to the inversion base at a height $Z_{i}$. The budgets are simplified if we use pressure coordinates. We define a layer average as [Deardorff et al., 1974]

$$
\langle\xi\rangle^{x i}=\left(1 / \Delta p_{i}\right) \int_{p_{s}}^{p_{1}} \bar{\xi} d p
$$

where $\Delta p_{i}-\left(p_{i}-p_{s}\right)--\langle\bar{\rho}\rangle_{g} Z_{i}$ is negative.

The mixed layer average budgets can be written as

$$
\overline{\left(\overline{\omega^{\prime} \xi_{s}^{\prime}}-\overline{\omega^{\prime} \xi_{i}^{\prime}}\right) / \Delta p_{i}+\left(\partial p_{i} / \partial t-\overline{\omega_{i}}\right)\left(\bar{\xi}_{i}-(\bar{\xi})^{d}\right) / \Delta p_{i}}
$$

where the subscripts $s$ and $i$ denote values at the surface and inversion base, respectively, and $\omega=-\rho g w$. The last term on the right-hand side has two components [see Deardorff et al., 1974; Betts, 1974]. The term $\partial p_{i} / \partial t\left(\bar{\xi}_{t}-(\bar{\xi})^{+s}\right)$ comes from differentiating (3), which defines $\langle\bar{\xi}\rangle{ }^{i}$ up to a moving boundary $p_{i}$, which increases as the BL deepens. The corresponding term in $\omega_{i}$ comes from the integration of the subsidence term $\bar{\omega} \partial \bar{\xi} / \partial p$ in (2'), with the small approximation of constant divergence between $p_{s}$ and $p_{i}$. Together, these terms can be written as an entrainment term

where

$$
\begin{gathered}
\omega_{e}\left(\bar{\xi}_{i}-\langle\bar{\xi}\rangle \dot{)}\right) \\
\omega_{e}=\left(\partial p_{i} / \partial t-\bar{\omega}_{i}\right)
\end{gathered}
$$

is the deepening of the layer by entrainment (negative in $p$ coordinates).

The choice of the level $p_{i}$ is important to the conceptual analysis. Convectively mixed boundary layers have a capping inversion, a transition or interfacial layer [Deardorff, 1979; Ludlam, 1980], which separates the fully turbulent layer below from the stably stratified and relatively nonturbulent free atmosphere above. From the sondes, we estimated two levels, $p_{i}$ and $p_{t}$, at the base and top of this capping inversion. For $p_{i}$ at the base of the inversion, $\bar{\xi}_{i}-\langle\bar{\xi}\rangle^{s i}$ is typically small and $\overline{\omega^{\prime} \bar{\xi}_{i}}$ is the larger term [Betts, 1974]. Capping inversions in the atmosphere are associated with strong divergence in the vertical turbulent flux of heat [Betts, 1974; Deardorff, 1979]. If the "mixed" layer were truly well mixed, with constant $\bar{\xi}-\langle\bar{\xi}\rangle^{-t}$ up to $p_{i}$, then the term denoted (6) disappears below the inversion, and the fluxes $\overline{\omega^{\prime} \xi^{\prime}}$ are linear between the surface and the $p_{i}$, where the heat flux reaches its maximum negative value [Deardorff et al., 1974]. When we use the mixed layer model to estimate the inversion level fluxes by the budget method, we get a parametric representation of the total effect of the entrainment process on the evolution of the mean layer below the inversion base. Formally, we rewrite (5) as

$$
\partial\left(\bar{\xi} / d / \partial t-g\left(F_{s \xi}-F_{i \xi}\right) / \Delta p_{i}\right.
$$

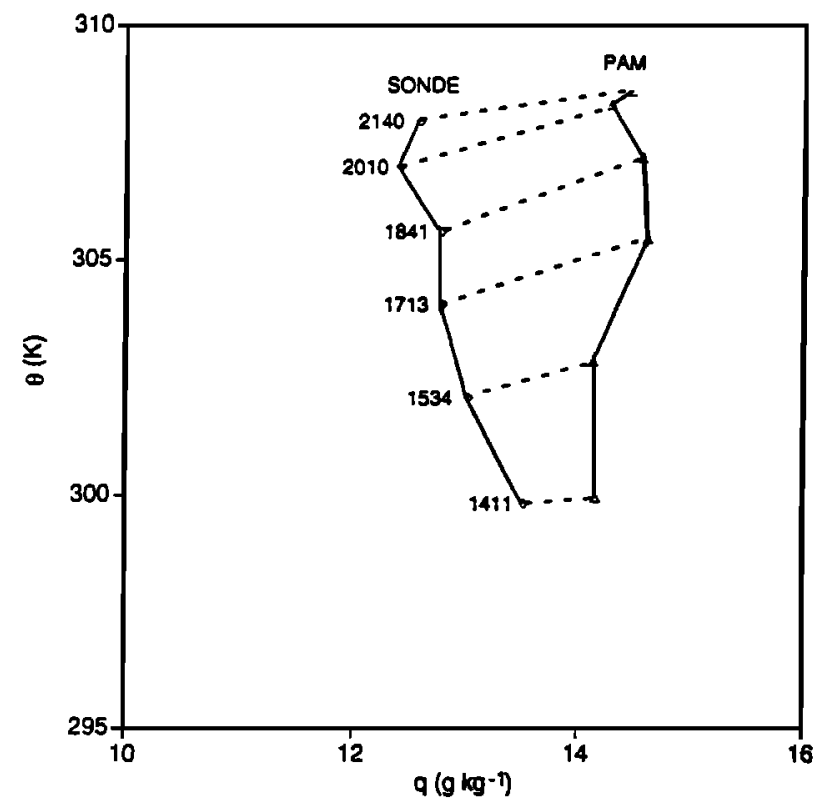

Figure 9. As Fig 8 for 13-day mean in IFC 3. 


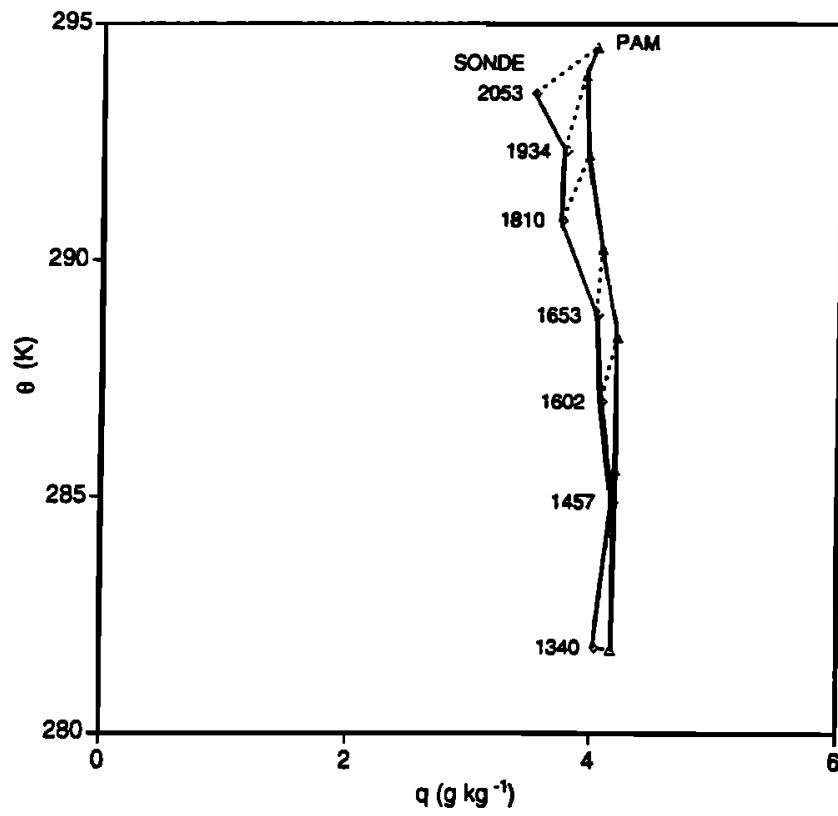

Figure 10. As Fig 8 for 6-day mean in IFC 4.

where

$$
\begin{gathered}
g F_{s \xi}=-\overline{\omega^{\prime} \xi_{s}^{\prime}} \\
g F_{i \xi}=-\omega^{\prime} \xi_{i}^{\prime}
\end{gathered}+\omega_{e}(\bar{\xi}-\langle\bar{\xi}\rangle) .
$$

The fluxes represented by $F_{i \xi}$ are the equivalent mixed layer fluxes at the inversion base, and it is these that are determined by our analysis. In this way the budget of the mixed layer formally includes the effects of the stratification within the $B L$, coupled to the subsidence and boundary layer growth, as part of the entrainment fluxes, that are typically warming and drying the mixed layer.

The budget equation (5') includes the pressure thickness of the mixed layer $\Delta p_{i}-\left(p_{i}-p_{j}\right)$. The inversion base, $p_{i}$, was determined for each sonde and used to scale the BL depth. The appropriate surface pressure, $p_{s}$, over the FIFE area of rolling hills is less obvious. The balloon launch site is near the north of the site at a relatively low elevation of $340 \mathrm{~m}$ [Sugita and Brutsaert, 1990A]. For their nearsurface analysis these authors used a lower reference height of $330 \mathrm{~m}$. For our purposes we need a pressure thickness for the mixed layer, representative of much larger space scales. We used the near-surface pressure of the FIFE PAM stations for $p_{s}$. These stations are at an average height near $407 \mathrm{~m}$; with a near surface pressure approximately $7.5 \mathrm{mbar}$ below the surface pressure of the sonde site. Although this correction to $p_{s}$ may seem small in comparison with $\Delta p_{i} \sim 100$ mbar, it is a potential source of bias in our budget estimates, since it directly reduces the BL flux divergence in (5'). It can be seen from (5') (and Table 2 below) that by reduction of $\Delta p_{i}$ by, say, $7 \%$ reduces the magnitude of the inversion level heat flux, and consequently our estimate of the closure parameter $A_{R}$ in (13) (see below), by a larger percentage.

\subsection{Inversion Level Budget}

A second estimate of the equivalent mixed layer fluxes can be made from the budget of the inversion layer between $p_{i}$ and $p_{t}$. This stable structure is maintained as the BL deepens, because of the downward eddy heat flux at $p_{2}$ [Betts, 1974], while at inversion top $p_{t}, \overline{\omega^{\prime} \xi_{t}^{\prime}}=0$. This inversion layer is thin, except during early morning periods when the BL sometimes deepens rapidly into a fossil BL, left from a previous day's convection [Nelson et al., 1989]. As with BL depth, individual radiosonde ascents do not give a good estimate of this inversion layer thickness, but we again assume that by averaging over many sondes and days, we get an estimate which is adequate for budget purposes. We find that this mean inversion thickness varies by only a few millibars during the day (in the range 15-20 mbar), much less than the rise of $p_{i}$. So to good approximation, we may assume a constant inversion thickness $\Delta p-p_{\varepsilon}-p_{i}$; so that $\partial p_{i} / \partial t=\partial p_{t} / \partial t$. The inversion layer budget then simplifies to

$$
\begin{gathered}
\Delta p \partial\langle\bar{\xi}\rangle^{i \xi} / \partial t-\overline{\omega^{\prime} \xi_{i}^{\prime}}+\partial p_{i} / \partial t\left(\overline{\xi_{j}}-\overline{\xi_{i}}\right) \\
\text { Combining with } \left.(\bar{T}) \text { and }(8 \mathrm{~b}) \text { gives (neglecting } \omega_{i}\right) \\
g F_{i \xi}=\partial p_{i} / \partial t(\bar{\xi}-(\bar{\xi}) \dot{ })+\Delta p \partial(\bar{\xi}) / \partial t
\end{gathered}
$$

The last term can be regarded as a correction, which reduces the entrainment fluxes and which disappears for an infinitesimally thin inversion. If $\Delta p \rightarrow 0$ and the layer below the inversion is well mixed, the product of the inversion rise and the jump of $\xi$ across the inversion gives the entrainment flux into the mixed layer.

In practice, we determined $\theta_{t}$ and $q_{t}$ for each sonde and averaged these to give $\bar{\xi}_{f}$. From the averaged sondes we found $\partial p_{i} / \partial t$ and a mean value of $\Delta p$ and $\partial\langle\bar{\xi}\rangle / \partial t$. We used (10) to get a second estimate of $F_{i \xi}$ (one which neglects $\left.\omega_{i}<<\partial p_{i} / \partial t\right)$. Yet another form of $(10)$ of interest is given in the Appendix.

\subsection{Inversion Level Bowen Ratio}

Using the same notation as (8), the $\theta$ and $q$ fluxes in watts per square meter are

$$
\begin{gathered}
F_{\theta}=-C_{p} \overline{\omega^{\prime} \theta^{\prime}} / g \\
F_{q}=-L \overline{\omega^{\prime} q^{\prime}} / g
\end{gathered}
$$

Both the right-hand terms of $F_{i \xi}$ in (8B) involve the coupling of the $\theta$ and $q$ gradients just below and through the inversion, where the entrainment is taking place. So we can approximately define an inversion level Bowen ratio $\beta_{i}$

$$
\beta_{i}-F_{i \theta} / F_{i q}=\left(C_{p} / L\right)(\partial \bar{\theta} / \partial \bar{q})_{i}
$$

This Bowen ratio, $\beta_{i}$, was also estimated from the mean radiosonde profiles for $1<\hat{p}<1.05$. It serves as a check on our estimates of the inversion level fluxes.

\subsection{Closure Equation for Inversion Level Fluxes}

Dry mixed layer models [Betts, 1973; Carson, 1973; Tennekes, 1973] relate the inversion base virtual heat flux to the surface virtual heat flux, using a closure parameter $A_{R}$

$$
F_{i \theta_{v}}=-A_{R} F_{s \theta_{v}}
$$

With constant $A_{R}$ this is a highly simplified formula for the entrainment process. Turbulence in the BL drives entrainment and the arguments used to derive (13) (loc. cit) focused on the generation of turbulence by the buoyancy flux at the surface. Mechanical production of turbulence can drive entrainment [Stull, 1976A] and, consequently, in a sheared 
layer, $A_{R}$ can vary during the diurnal cycle [Stull, 1976B, 1988] as the relative amounts of buoyant and mechanical production change. In this paper we shall use (13) to estimate a daytime mean value of $A_{R}$. The uncertainties in our values of $A_{R}$ are considerable, and we shall only make one attempt to estimate the dependence of $A_{R}$ on mechanically driven turbulence, by stratifying the June/July and August days into low and high wind regimes.

The virtual heat fluxes in (13) are related to the heat and moisture fhuxes given by (11), with slight approximation [Deardorff, 1980]

$$
\begin{aligned}
& F_{s \theta_{v}}-F_{s \theta}+\delta \in F_{s q} \\
& F_{i \theta_{v}}-F_{i \theta}+\delta \in F_{i q}
\end{aligned}
$$

where $\delta \epsilon=0.608 C_{p} T L=0.07$ and $T$ is temperature. We shall use the measured surface fluxes to find $F_{\theta_{v}}$ in (14A), and use the estimated inversion level fluxes to find $F_{s \theta_{v}}$ in (14B). This will give us two estimates of $A_{R}$ for each set of sonde averages, one from the mixed layer budget and one from the inversion layer budget.

Substituting the Bowen ratio $\beta_{i}$ at the inversion from (12A), and a similar equation for the surface,

$$
\beta_{s}-F_{s \theta} / F_{s q}
$$

gives the inversion level fluxes of sensible and latent heat as

$$
\begin{gathered}
F_{t \theta}--A_{R} F_{s \theta}\left(1+\delta \in \beta_{s}\right) /\left(1+\delta \in \beta_{i}\right) \\
F_{t q}-F_{i \theta} / \beta_{i}
\end{gathered}
$$

The surface heat flux and $\beta_{s}$ were found from an average of 17 surface flux stations (as discussed in section 2.2), and $\beta_{i}$ is from (12). The terms in parentheses in (15A) come from the density effects of water vapor and hence the latent heat flux, because (13) is expressed in terms of virtual heat flux. These terms are $\approx 1$ for large Bowen ratios. We will also use (15) to estimate June/July and August inversion level flux estimates, subject to a constraint on inversion level Bowen ratio estimated using (12). This was the method used by Betts et al. [1992].

\section{Estimates of Inversion Level Fluxes and Closure Parameter $A_{R}$}

We first calculated the BL-top fluxes by integrating the budget equation ( $\left.5^{\prime}\right)$ from the surface to the top of the mixed layer. Then we calculated the BL-top fluxes from the deepening of the $\mathrm{BL}$ and the jumps at $\mathrm{BL}$ top using the inversion layer budget (10). We then explore the use of a BL-top Bowen ratio constraint and make further estimates of $A_{R}$ for June/July and August.

It is difficult to assess errors in analyses of composite data such as this. The variance of our six independent estimates of $A_{R}$ gives some indication of the actual overall uncertainties in the method, or the variability in the physical process. The errors given in Tables 2 and 3 show the propagation of plausible errors through the formulae. However, it is unknown systematic errors that are of concern. We have no estimates of the mean horizontal advection of heat or moisture for the days in the composite, which would affect the budget method. We have no measurements of vertical advection, which is neglected in the inversion rise estimate.
Since the values of $A_{R}$ from this method are all smaller than the budget method (see Tables 2 and 3 below), this suggests that vertical advection may be a significant component in the daytime inversion budget.

\subsection{Budget Method}

We determined the inversion level fluxes from (5') between each sonde time and then averaged the results over the day from 1400 to 2130 UT for IFCs 2 and 3 and to 2030 UT for IFC 4 . Table 2 summarizes the heat and moisture budgets for the three sonde sequences. Budgets for individual 90-min time steps between sonde averages are noisy, but errors in average $\theta$ or $q$ at one time introduce largely compensating errors in the average (see section 3.2). Table 2 shows the Bowen ratios at the surface and inversion for these average budgets, the virtual heat fluxes derived from (14), and the corresponding closure parameter derived from (13). For Table 2 we assumed a $10 \%$ error in the surface fluxes, a $5 \%$ error in $\Delta p_{i}$, and errors in the time change of $\theta$ and $\mathrm{q}$ over the budget period of $0.5 \mathrm{~K}$ and $0.5 \mathrm{~g} \mathrm{~kg}^{-1}$ respectively. We then combined these errors assuming them to be random to show resultant errors in the derived terms: Bowen ratio, inversion level fluxes, and $A_{R}$.

We see the rise in surface Bowen ratio with season as the soil moisture drops from spring to fall. The inversion level moisture flux is comparable to the surface moisture flux, consistent with the nearly constant mixing ratio during the day in Figures 2, 4, and 6. The three mean values of $A_{R}$ vary considerably, suggesting that even after averaging, the calculation of inversion level fluxes as a budget residual is either not very accurate or that the physical process is quite variable.

The chief uncertainty is whether horizontal advection (which we do not measure) is significant in the mean budget. The large value found for IFC 3 of $A_{R}=0.85$ could result partly from warm advection in the 13-day average. If there is an average of $1 \mathrm{~K}$ of warm advection during the day between 1400 and $2130 \mathrm{UT}$, the budget from the sonde mean will give an inversion level heat flux $F_{i \theta}$ that is high by $35 \mathrm{Wm}^{-2}$, and the corresponding value of $A_{R}$ is reduced in magnitude from 0.85 to 0.60 . Similarly, dry advection of $1 \mathrm{~g} \mathrm{~kg}^{-1}$ during the same period increases the estimate of $F_{i q}$ by $87 \mathrm{Wm}^{-2}$, although the impact of this on $A_{R}$ is small.

Table 3. Estimation of $A_{R}$ from BL growth.

\begin{tabular}{cccccc}
\hline & $F_{\nu \theta}$ & $F_{\nu q}$ & & $F_{v \nu}$ & $A_{R}$ \\
IFC & $\mathrm{W} \mathrm{m}^{-2}$ & $\mathrm{~W} \mathrm{~m}^{-2}$ & $\beta_{i}$ & $\mathrm{~W} \mathrm{~m}^{-2}$ & $\mathrm{~W} \mathrm{~m}^{-2}$ \\
\hline 2 & -62 & 265 & -0.23 & -43 & 0.38 \\
& \pm 16 & \pm 67 & \pm 0.08 & \pm 11 & \pm .10 \\
3 & -63 & 343 & -0.18 & -39 & 0.28 \\
& \pm 16 & \pm 86 & \pm 0.06 & \pm 10 & \pm 0.07 \\
4 & -83 & 151 & -0.55 & -73 & 0.31 \\
& \pm 21 & \pm 38 & \pm 0.19 & \pm 18 & \pm 0.08 \\
& & & & & 0.32 \\
\hline
\end{tabular}




\subsection{Inversion Rise Method}

Table 3 summarizes the average inversion level fluxes calculated by integrating (10) from 1400 to 2130 for IFCs 2 and 3 and to 2030 for IFC 4 . Substituting these fluxes and the surface fluxes from Table 1 in (13) gives values of $A_{R}$ which range from 0.28 to 0.39 . The error values shown are again simple estimates, based on the $10 \%$ error in the surface fluxes used in Table 2, and an assumed $25 \%$ error in the inversion level fluxes, whose accuracy is hard to assess. This method involves uncertainty in the definition of the jumps in $\theta$ and $q$ at the inversion and the inversion level thickness $\Delta p$, but it is less subject than the budget method to uncertainties caused by horizontal advection. For example, only if there were systematic advection of deeper BLs over the FIFE site would these inversion flux estimates be biased high. Instead, this method neglects vertical advection, because we neglect $\bar{\omega}_{i}$ in $(7)$ in comparison with $\partial p / \partial t$. We have no measurements of $\bar{\omega}_{i}$, but in the suppressed convective conditions characteristic of summer days, it is likely to be comparable to or greater than the radiative equilibrium subsidence rate of the order of $40 \mathrm{mbar} / \mathrm{d}$. The neglect of $\overline{\omega_{l}}$ would then lead to a $10 \%$ (or more) underestimate of $A_{R}$ from this method.

\subsection{Discussion of Methods}

If we compare the estimates of entrainment rate and fluxes at BL top for these two methods, we see close agreement for the October sonde time series, when the surface heat flux is high. October also gives the two lowest estimates for $A_{R} \sim 0.3$. However, Betts et al. [1992] speculated (from comparisons of the surface flux measurements with aircraft flux measurements at $70 \mathrm{~m}$ above ground) that these October sensible (latent) heat fluxes might be biased high (low) by about $30 \mathrm{~W} \mathrm{~m}^{-2}$. Such an error would increase the October budget estimate of $A_{R}$ to 0.48 and the inversion rise estimate to 0.39 .

For June/July, both methods give $A_{R}-0.4$. The two estimates of inversion level heat flux, $F_{i \theta}$, agree quite well, but $F_{i q}$ from the budget method is high and questionable.
The sonde average at 2143 UT (see Figure 8) may be unrepresentatively dry. However, this has only a small impact on $A_{R}$.

In August the budget method gives a large $F_{i \theta}$ and the corresponding $A_{R}$ of 0.85 is large, whereas the inversion rise estimates are much smaller. The only explanation we have is that there may have been significant warm advection in August even in the mean. This would affect both methods in opposite directions. For example, a mean horizontal warm advection of $0.25 \mathrm{~K} \mathrm{~h}^{-1}$ between the surface and $p_{t}$ (quite a large value) during the analysis period from 1400 to 2130 UT would alter both estimates of $F_{i \theta}$ to $-74 \mathrm{~W} \mathrm{~m}^{-2}$, with a corresponding value for both methods of $A_{R}$ of 0.36 .

From Tables 2 and 3 we have six values from the three budgets for the $B L$ entrainment parameter with a mean $A_{R}$ $=0.44 \pm 0.21$. This is similar to the values of $0.43 \pm 0.12$ and $0.38 \pm 0.16$ found by Betts et al. [1990, 1992] for the FIFE area using aircraft data sets. It increases our confidence that the $\mathrm{BL}$ entrainment over the FIFE area is large. A value of $A_{R} \approx 0.4$ is double that which has been considered representative for free convective BLs [Stull, 1988]. There are a wide range of mean winds in our set of days, so shear-induced mixing may be partly responsible for increasing entrainment particularly in June/July and August, when the surface sensible heat fluxes are lower. We will make an estimate of the effect of the surface shear on $A_{R}$ in the next section. The (weak) suggestion that $A_{R}$ may be smaller, when the surface heat flux is high, is consistent with the work of Dubosclard [1980]. The main impact of high entrainment is that the BL does not moisten over the FIFE area during its daytime growth, because of the greater downward mixing of dry air. Comparative studies of the BL climate in the European Centre forecast model [Betts et al., 1993], which has very little BL-top entrainment, show the large impact of this entrainment on the afternoon BL equilibrium of moisture and equivalent potential temperature.

The inversion level Bowen ratio gives a check on the fluxes derived from the two methods; and it can also be used as a constraint on the estimation of $A_{R}$. Table 4 lists the inversion level Bowen ratio $\beta_{i}$ calculated from the budgetderived fluxes, from the BL-top rise derived fluxes, and

Table 4. Further Estimates of Inversion Level Bowen Ratio and $A_{R}$

\begin{tabular}{|c|c|c|c|c|c|c|c|c|}
\hline \multirow[b]{3}{*}{ IFC } & \multirow[b]{3}{*}{ Budget } & \multirow{2}{*}{\multicolumn{2}{|c|}{$\beta_{\imath}$}} & \multirow[b]{3}{*}{$\left(p_{i}, p_{\nu}\right)$} & \multicolumn{4}{|c|}{$A_{R}$} \\
\hline & & & & & \multicolumn{2}{|c|}{ Budget } & \multicolumn{2}{|c|}{ BL top } \\
\hline & & BL Top & $(1.0,1.05)$ & & from $F_{i \theta}$ & from $F_{\text {qq }}$ & from $F_{i \theta}$ & from $F_{u q}$ \\
\hline 2 & $\begin{array}{r}-0.21 \\
\pm 0.06\end{array}$ & $\begin{array}{l}-0.23 \\
\pm 0.08\end{array}$ & -0.28 & -0.32 & 0.55 & 0.74 & 0.41 & 0.50 \\
\hline 3 & $\begin{array}{l}-0.42 \\
\pm 0.10\end{array}$ & $\begin{array}{r}-0.18 \\
\pm 0.06\end{array}$ & -0.29 & -0.31 & 0.78 & 0.54 & 0.34 & 0.54 \\
\hline 4 & $\begin{array}{r}-0.75 \\
\pm 0.39\end{array}$ & $\begin{array}{r}-0.55 \\
\pm 0.19\end{array}$ & $(-1.06)$ & $(-1.03)$ & - & - & - & - \\
\hline \multicolumn{4}{|c|}{ IFC 2 and 3 mean } & & \multicolumn{2}{|c|}{$0.65 \pm 0.13$} & \multicolumn{2}{|c|}{$0.45 \pm 0.09$} \\
\hline
\end{tabular}


from (12), first using the gradient for $1.0<\hat{p}<1.05$, and finally the gradient across the inversion from $p_{i}$ to $p_{r}$. We have bracketed some October values since the vertical $q$ gradients widely vary, and these averages cannot be considered representative. The difference between columns 1 and 2 reflect the difference in the inversion-level fluxes in Tables 2 and 3 . The error estimates are also from those tables. For the estimates of $\beta_{i}$ from the mean profiles we have not attempted to estimate errors. The difference between columns 2 and 4 reflect the correction term in $\Delta p$ in (10). If the inversion layer $\Delta p \rightarrow 0$, then by definition, $\beta_{i}$ (BL top) would equal $\beta\left(p_{i}, p_{v}\right)$. For June/July and August the profile estimate close to the inversion base is slightly less than $\beta\left(p_{i}, p_{i}\right)$, but $\beta_{i}$ (BL top) is smaller still because of the term in $\Delta p$ in (10). We do not know whether to attribute this difference to a smoothing of the profiles by the averaging, which might bias $\beta_{i}$ high, or to errors in the BL-top budget.

Our conclusions are limited. For the June/July budget the low value of $\beta_{i}$ (budget) confirms that the $F_{i q}$ (budget) is probably too high. For August the value of $\beta_{i}$ for $1.0<\hat{p}<1.05$ is between $\beta_{i}$ (budget) and $\beta_{i}$ (BL top), suggesting that $F_{i 0}$ is also between the corresponding values. We have discussed how warm temperature advection could be responsible for this. For October any comparison of profile estimates of $\beta_{1}$ is questionable, because the average contains widely different vertical gradients of $q$.

There is one further method using equation (15) for estimating values for $A_{R}$ (which was used by Betts et al., [1992]), which gives similar weights to the heat and moisture fluxes at the inversion. The $\beta_{s}$ is calculated from the surface fluxes in Table 2, and we insert $\beta_{i}$ (from Table 4) from the profiles for the layer $1<\hat{p}<1.05$ and then calculate $A_{R}$ from the values of $F_{i \theta}, F_{i q}$ in Tables 2 and 3. This gives the set of eight estimates of $A_{R}$ in Table 4 for June/July and August. The estimates from $F_{i \theta}$ are close to the direct calculations using $F_{i \theta_{*}}$ in Tables 2 and 3 (which do not constrain $\beta_{i}$ ). As discussed above, the highest values of $A_{R}$ of 0.74 and 0.78 may reflect horizontal advection of dry air in June/July and warm air in August. The mean from the budget fluxes is again higher than from the BL-top rise: this difference is probably partly due to the neglect of $\bar{\omega}$ in (7), in the BL-top rise method, as mentioned earlier. Our conclusions are again limited. The estimates of $A_{R}$ in Table 4 are consistent with those in Tables 2 and 3, although they are generally a little higher. They do show that the inversion level moisture fluxes are consistent with $A_{R} \approx 0.4$ to 0.5 .

\subsection{Effect of Surface Wind Shear}

As discussed above, the composite method has its limitations. We do not have sufficient data to stratify over a range of wind conditions to assess the role of the surface wind shear in generating mechanical turbulence. (There is little shear across the inversion on most days.) However, by combining the June/July and August days, we can group them into high and low wind classes. Choosing a threshold of $7 \mathrm{~ms}^{-1}$ for the mean BL wind (between 1400 and 2130 UT) gives two groups of 10 days. The low wind group (comprising June 26 and 27, July 1, and August 9, 10, 11, 16,17 , and 18) has a mean BL wind speed of $4.8 \mathrm{~ms}^{-1}$ and the high wind group (comprising July 6, 9, 10, and 11 and August $6,7,15,19,20$, and 21) has a mean BL wind speed of $11.3 \mathrm{~ms}^{-1}$. The mean wind shears across the inversion are small (1-2 ms in the low wind group and 2-3 $\mathrm{ms}^{-1}$ in the high wind group). We will not attempt to estimate the friction velocity corresponding to these wind speeds, because there is some uncertainty over the surface roughness $\left(Z_{O M}\right)$ for the FIFE area. Sugita and Brutsaert [1990] made an indirect estimate of $Z_{O M}$ of $1.05 \mathrm{~m}$ using the rawinsonde wind profiles. However, Betts and Beljaars [1993] derived a smaller value of $Z_{O M}$ of $0.19 \mathrm{~m}$ from aircraft momentum flux measurements at roughly $100 \mathrm{~m}$ above the surface.

Table 5 summarizes the budget and inversion rise estimates of the inversion level fluxes and entrainment parameter $A_{R}$ for these two wind groups. There are some differences. The low wind case has a larger surface sensible heat flux, but the BL is relatively cool and dry with a weaker BL-top inversion. The high wind values of $A_{R}$ are both larger than the low wind values, suggesting that mechanical turbulence is driving more entrainment in the high wind case. However, the budget estimates (which neglect horizontal advection, which appeared to be significant in August in Table 2) are both much larger than the corresponding inversion rise estimates (which neglect subsidence and therefore underestimate $A_{R}$ ). So we conclude that the data suggest a significant role for mechanically driven entrainment, but the uncertainties are large, and a quantitative estimate cannot be made.

Table 5. IFC 2 and IFC 3 Data Partitioned by Wind Speed

\begin{tabular}{|c|c|c|c|c|c|c|c|c|}
\hline \multirow[b]{2}{*}{$\begin{array}{c}\text { Mean } \\
\text { Windspeed } \\
\mathrm{ms}^{-1}\end{array}$} & \multirow[b]{2}{*}{$\begin{array}{c}F_{\mathrm{St}} \\
\mathrm{W} \mathrm{m}^{-2}\end{array}$} & \multirow[b]{2}{*}{$\begin{array}{c}F_{S q} \\
\mathrm{~W} \mathrm{~m}^{-2}\end{array}$} & \multicolumn{3}{|c|}{ Budget } & \multicolumn{3}{|c|}{ BL growth } \\
\hline & & & $\begin{array}{l}F_{v \theta} \\
\mathrm{W} \mathrm{m}^{-2}\end{array}$ & $\underset{\mathrm{W} \mathrm{m}^{-2}}{F_{q q}}$ & $A_{R}$ & $\mathrm{~W}_{\mathrm{m}^{-2}}$ & $\underset{\mathrm{W}^{\mathrm{m}^{-2}}}{\boldsymbol{F}_{\mathrm{q}}}$ & $A_{R}$ \\
\hline 11.3 & 94 & 315 & -114 & 274 & $\begin{array}{l}-0.81 \\
( \pm 0.2)\end{array}$ & -66 & 318 & $\begin{array}{l}-0.38 \\
( \pm 0.1)\end{array}$ \\
\hline 4.8 & 124 & 282 & -122 & 477 & $\begin{array}{c}-0.61 \\
( \pm 0.2)\end{array}$ & -48 & 317 & $\begin{array}{l}-0.18 \\
( \pm 0.1)\end{array}$ \\
\hline
\end{tabular}




\section{Conclusions}

We have analyzed the diurnal cycle of the dry convective BL over FIFE during three seasons (June/July, August, and October) by averaging radiosondes in pressure coordinates scaled by BL depth. The mean profiles show a pattern of deepening and warming during the daytime with little change of mixing ratio. Their vertical structure is consistent with earlier studies. We used these time sequences of mean sondes to estimate the fluxes of heat and moisture at BL top. From these we estimated an entrainment closure parameter $A_{R}$, the ratio of virtual heat flux at the inversion base to the surface virtual heat flux. We found $A_{R}=-0.44 \pm 0.21$ comparable to the values found by Betts et al. $[1990,1992]$ using aircraft data for the same FIFE experiment. This value is roughly double the value of -0.2 that has been considered representative of free convective BLs [Stull, 1988], which has been incorporated explicitly or implicitly in many simple model parameterizations. Dubosclard [1980], however, found similar large values. Another study [Culf, 1992] over the Sahel has also estimated $A_{R}$ to be large. We divide the June/July and August days into two groups of high and low wind speed. The estimates of $A_{R}$ from these suggest that mechanically driven turbulence may be contributing significantly to entrainment, but the uncertainties are large. Shallow BL cumulus may also play some role in increasing entrainment, particularly in June/July and perhaps also in August.

BL-top entrainment plays a critical role in the diumal evolution of the BL over land: particularly in determining the afternoon moisture and equivalent potential temperature equilibrium. This in turn determines the likelihood of occurrence of deep convection over a region. This uncertainty in the magnitude of the entrainment parameter $A_{R}$ is significant in modeling of the land surface BL and needs further study.

\section{Appendix}

Two further manipulations of the budget equations are of interest. The first illustrate a different method of estimating the inversion base flux from the inversion rise. If we assume the inversion maintains constant "jumps" in $\Delta \xi$ as the BL deepens,

$$
\partial\langle\bar{\xi}\rangle / \partial t-\partial \bar{\xi}_{t} / \partial t-\Gamma_{\xi} \partial p_{i} / \partial t
$$

where $\Gamma_{\xi}-\partial \bar{\xi} / \partial p$ above the inversion. For the $\theta$ budget we then recover [Betts, 1974]

$$
g F_{i \theta}-\partial p_{i} / \partial t\left(\overline{\theta_{t}}-\langle\bar{\theta}\rangle^{i}-\Gamma_{\theta} \Delta p\right)
$$

We shall however use (10) in this paper, since it is straightforward to estimate the time derivatives for the inversion from the data.

One other derivation shows the relationship of the budgets found by integrating to inversion base or inversion top. If we combine (5), (8), and (10), and assume for simplicity that the inversion warms at the same rate as the mixed layer

$$
\partial\langle\bar{\xi}\rangle^{\dot{u}} / \partial t-\partial\langle\bar{\xi}\rangle^{s i} / \partial t
$$

we get

$$
\Delta p_{z} \partial\langle\bar{\xi}) \Delta / \partial t--g F_{s \bar{\xi}}+\partial p_{1} / \partial t\left(\bar{\xi}_{t}-\langle\bar{\xi})^{s i}\right)
$$

The budget for the layer from surface to inversion top is

$$
\Delta p_{t} \partial(\bar{\xi}) \approx / \partial t=-g F_{s \bar{\xi}}+\partial p_{t} / \partial t\left(\bar{\xi}_{t}-\langle\bar{\xi})^{\Delta t}\right)
$$

(A3) and (A4) are equivalent, given our assumptions of (A2) and $\Delta p$ constant, because their difference can be written as

$$
\begin{aligned}
& \Delta p_{t} \partial(\bar{\xi})=\pi / \partial t+\langle\bar{\xi}\rangle=\approx p_{t} / \partial t \\
& \text { - } \left.\Delta p_{i} \partial\langle\bar{\xi}\rangle \dot{s i} / \partial t+\langle\bar{\xi}\rangle\right)^{i} \partial p_{i} / \partial t+\Delta p \partial\langle\bar{\xi}\rangle\langle i / \partial t
\end{aligned}
$$

Acknowledgments. This research was supported by NASAGSFC under contract NAS5-20134 (task 47) and NAS5-32334 and the National Science Foundation under grant ATM9001960. I am grateful to Roland Stull for useful suggestions.

\section{References}

Ball, F. K., Control of inversion height by surface heating, $Q$. J. R. Meteorol. Soc., 86, 483-494, 1960.

Betts, A. K., Non-precipitating cumulus convection and its parameterization, Q.J.R. Meteorol. Soc., 99, 178-196, 1973.

Betts, A. K., Reply to Deardorff et al [1974], Q.J.R. Meteorol. Soc., 100, 469-472, 1974.

Betts, A. K., Modelling subcloud layer structure and interaction with a shallow cumulus layer, J. Atmos. Sci., 33, 2363-2382, 1976.

Betts, A. K., Budget analyses of the FIFE atmospheric boundary layer, J. Geophys. Res., 97, 18,523-18531, 1992.

Betts A. K., and J. H. Ball, FIFE-1987 mean surface data time series, available on diskette from author, Atmos. Res., 1992.

Betts, A. K. and A. C. M. Beljaars, Estimation of effective roughness length for heat and momentum from FIFE data, Atmos Res in press, 1993.

Betts, A. K., J. H. Ball, and A. C. M. Beljaars, Comparison between the land surface response of the European Centre model and the FIFE-1987 data. Q. J. R. Meteorol.Soc., 119, 975-1001, 1993.

Betts, A. K., R. L. Desjardins, J. I. MacPherson, and R. D. Kelly, Boundary layer heat and moisture budgets from FIFE. Boundary Layer Meteorol., so, 109-137, 1990.

Betts, A. K., R. L. Desjardins, and J. I. MacPherson, Budget analysis of the boundary layer grid flights during FIFE 1987. J. Geophys. Res., 97,19,533-18,546, 1992.

Carson, D. J., The development of a dry inversion-capped convectively unstable boundary layer, $Q . J . R$. Meteorol.Soc., 99, 450-467, 1973.

Culf, A. D., An application of simple models to Sahelian convective boundary-layer growth, Boundary Layer Meieorol. 58, 1-18, 1992.

Deardorff, J. W., Prediction of convective mixed-layer entrainment for realistic capping inversion structure, J. Atmos. Sci., 36, 424-436, 1979.

Deardorff, J. W., Cloud-top entrainment instability, J. Atmos. Sci., 37, 131-147, 1980.

Deardorff, J. W., G. E. Willis, and D. K. Lilly, Comments on Betts [1973], Q.J.R. Meteorol. Soc., 100, 122-123, 1974.

Driedonks, A. G. M., Models and observations of the growth of the atmospheric boundary layer, Boundary Layer Meteorol., 23, 283-306, 1982.

Dubosclard, G., A comparison between observed and predicted values for the entrainment coefficient in the planetary boundary layer. Boundary Layer Meteor., 18, 473-483, 1980.

Kim J. and S. B. Verma, Components of surface energy balance in a temperate grassland ecosystem. Boundary Layer Meteor., 51, 401-417, 1990.

Lilly, D. K., Models of cloud-topped mixed layers under a strong inversion. Q. J. R. Meteorol. Soc., 94, 292-309, 1968.

Ludlam, F. H., Clouds and Storms, 405 pp., Pennsylvania State 
University Press, University Park, PA, 1980.

Mahrt, L., Mixed layer moisture structure. Mon. Weather Rev., 104, 1403-1407, 1976.

Nelson, E., R. Stull, and E. Eloranta, A prognostic relationship for entrainment zone thickness, J. Appl. Meteorol., 28, 885903, 1989.

Sellers, P. J., F. G. Hall, D. E. Strebel, and F. F. Murphy, The First ISLSCP Field Experiment (FIFE), Bull. Amer. Meteorol. Soc., 69, 22-27, 1988.

Smith E. A., et al., Area-averaged surface fluxes and their time-space variability over the FIFE experimental domain, J. Geophys. Res., 87, 18,599-18,622, 1992.

Smith, E. A., H. J. Cooper, W.L. Crosson, and D.D. Delorey, Retrieval of surface heat and moisture fluxes from slow launched radiosondes, J. Appl. Meteorol., 30, 1613-1626, 1991.

Stull, R. B., Inversion rise model based on penetrative convection. J. Atmos. Sci., 30, 1092-1099, 1973.

Stull, R. B., The energetics of entrainment across a density interface, J. Atmos. Sci., 33, 1260-1267, 1976A.

Stull, R. B., Mixed layer depth model based on turbulent energetics. J. Atmos. Sci., 33, 1268-1278, 1976B.

Stull, R. B., An Introduction to Boundary Layer Meterology.
666 pp., Kluwer, Norwell, Mass., 1988.

Sugita, M., and W. Brutsaert, Wind velocity measurements in the neutral boundary layer above hilly prairie. J. Geophys. Res., 95, 7617-7624, 1990A.

Sugita, M., and W. Brutsaert, How similar are temperature and humidity profiles in the unstable boundary layer? J. Appl. Meteorol., 29, 489-497, 1990B.

Tennekes, H., A model for the dynamics of the inversion above a convective boundary layer, J. Atmos. Sci., 30, 558-567, 1973.

Wyngaard, J.C. and R.A. Brost, Top-down and bottom-up diffusion of a scalar in the convective boundary layer. $J$. Atmos. Sci., 41, 102-112, 1984.

Zeman, $\mathbf{O}$. and $\mathbf{H}$. Tennekes, Parameterization of the turbulent energy budget at the top of the daytime atmospheric boundary layer, J. Atmos. Sci., 34, 111-123, 1977.

A. K. Betts and J. H. Ball, Atmospheric Research, RR 3, Box 3125, Pittsford, VT 05763.

(Received March 9, 1993; revised September 8, 1993; accepted September 24, 1993.) 